\title{
Concentrações e composições químicas do meio nutritivo para o cultivo in vitro de orquídea ${ }^{1}$
}

\author{
Donizetti Tomaz Rodrigues ${ }^{2}$, Roberto Ferreira Novais², Víctor Hugo Alvarez V. ${ }^{2}$, José Maria Moreira Dias ${ }^{3}$, \\ Ecila Mercês de Albuquerque Villani**
}

\begin{abstract}
RESUMO
Plântulas de orquídeas cultivadas in vitro respondem de forma distinta aos vários meios de cultura empregados nessa técnica. Este trabalho comparou o meio nutritivo Knudson C, utilizado no cultivo de orquídeas, com o denominado MN e outros dois meios preparados com fertilizantes Peters ${ }^{\circledR}$ : NPK 10-30-20 + micronutrientes e NPK 30-10-10 + micronutrientes para o cultivo in vitro de plântulas do híbrido Etibaia (Cattleya walkeriana x C. loddigesii), com seis meses de idade, germinadas sobre o meio Knudson C. Os três últimos meios foram testados com as seguintes doses de sais: 0,$25 ; 0,50 ; 1,00 ; 1,75$; e 2,25 $\mathrm{g} \mathrm{L}^{-1}$, e o meio Knudson C, 2,0 g L-1. A todos os meios adicionaram-se $20 \mathrm{~g} \mathrm{~L}^{-1}$ de sacarose, solidificado com $10 \mathrm{~g} \mathrm{~L}^{-1}$ de ágar, e o pH foi ajustado a 5, 7. Aos meios MN e Peters ${ }^{\circledR}$ foram acrescentados $2 \mathrm{~g} \mathrm{~L}^{-1}$ de carvão ativado e $200 \mathrm{ml} \mathrm{L}^{-1}$ de água de coco. Foram utilizados frascos de vidro de $320 \mathrm{~mL}$ contendo $35 \mathrm{~mL}$ de meio nutritivo, e o experimento foi mantido em sala de crescimento a $27 \pm 2{ }^{\circ} \mathrm{C}, 16 / 8 \mathrm{~h}$ luz/escuro e irrdiância de $48 \mu \mathrm{mol} \mathrm{m} \mathrm{s}^{-1}$. Melhores respostas para produção de matéria fresca foram obtidas com os fertilizantes NPK, em comparação com os meios Knudson C e MN. A produção de matéria fresca aumentou linearmente com o aumento da dose de nutrientes nos meios MN e nos dois NPK. As plântulas de orquídea cultivadas em meio Knudson $\mathrm{C}$ apresentaram os menores valores para as variáveis avaliadas.
\end{abstract}

Palavras-chave: nutrição, micropropagação, Orchidaceae.

\section{ABSTRACT}

\section{Chemical composition and component concentrations of culture medium for the in vitro growth of orchid}

Orchid seedlings grown in vitro respond differently to the different culture media used for this technique. This study compares the traditional Knudson (KC) medium used in orchid in vitro cultivation with a new medium formulation based on the KC medium with modifications, which was named Novais medium (NM), and two other media prepared with NPK fertilizer in the formulations 10-30-20 + micronutrients and 30-10-10 + micronutrients. The media were tested for the in vitro growth of six-month-old orchid seedlings derived from the cross Cattleya walkeriana $x$ Cattleya loddigesii 'Etibaia' and germinated in Knudson C medium. The $\mathrm{KC}$ medium was tested in the concentration of $2.0 \mathrm{~g} \mathrm{~L}^{-1}$, and the other three media were tested in the concentrations of $0.25 ; 0.50 ; 1.00 ; 1.75$; and $2.25 \mathrm{~g} \mathrm{~L}^{-1}$. All the media were added with $20 \mathrm{~g} \mathrm{~L}^{-}$ ${ }^{1}$ of sucrose, solidified with $10 \mathrm{~g} \mathrm{~L}^{-1}$ agar and $\mathrm{pH}$ adjusted to 5.7. $\mathrm{NM}$ and Peters ${ }^{\circledR}$ media were added with $2 \mathrm{~g} \mathrm{~L}^{-1}$ of activated charcoal and $200 \mathrm{ml} \mathrm{L}^{-1}$ of coconut water. The seedlings were cultured in $320 \mathrm{~mL}$ glass jars containing $35 \mathrm{~mL}$ of medium. The experiment was maintained in a growth room at $27 \pm 2{ }^{\circ} \mathrm{C}, 16 / 8 \mathrm{~h}$ photoperiod with $48 \mathrm{i} \mathrm{mol} \mathrm{m} \mathrm{s}^{-1}$ irradiance. The best responses for production of fresh matter were obtained using NPK fertilizers, in comparison with KC and NM medium. The fresh matter production increased linearly with increasing nutrients doses in both $\mathrm{MN}$ and KC media. The orchid seedlings grown in Knudson medium had the lowest means for the variables evaluated.

Key words: nutrition, micropropagation, Orchidaceae.

\footnotetext{
Recebido para publicação em 03/03/2010 e aprovado em 04/10/2011

Extraído da Dissertação de Mestrado do primeiro autor.

${ }^{2}$ Engenheiros-Agrônomos, Doutores. Departamento de Solos, Universidade Federal de Viçosa, Av. P. H. Rolfs, s/n, 36570-000, Viçosa, Minas Gerais, Brasil. donitom @ yahoo.com.br; rfnovais@ufv.br; vhav@ufv.br

${ }_{3}^{3}$ Engenheiro-Agrônomo, Doutor. Departamento de Fitotecnia, Universidade Federal de Viçosa, Av. P. H. Rolfs, s/n, 36570-000, Viçosa, Minas Gerais, Brasil. jmmdias@ ufv.br ${ }^{4}$ Engenheira-Agrônoma, Doutora. Pós-doutoranda. Departamento de Solos, Universidade Federal de Viçosa, Av. P. H. Rolfs, s/n, 36570-000, Viçosa, Minas Gerais, Brasil. ecilavillani@hotmail.com (*autor para correspondência)
} 


\section{INTRODUÇÃO}

Inúmeros meios de cultivo são utilizados para a propagação germinativa ou clonal in vitro de orquídeas do grupo Cattleya, com variada composição de sais, fontes de carbono, substâncias orgânicas, vitaminas e reguladores de crescimento (Arditti, 1992).

Os vários meios de cultura e as formulações NPK têm sido testados para diversos gêneros de orquídeas. $\mathrm{O}$ meio de cultura conhecido como MS (Murashige \& Skoog, 1962), utilizado com frequência nos trabalhos científicos, foi substituído por um meio desenvolvido por Novais \& Rodrigues (2004), contendo macro e micronutrientes mais açúcar e ágar. Os resultados encontrados com a nova formulação foram tão bons como aqueles obtidos com o meio MS, extremamente complexo e de custo elevado. Esses autores verificaram que formulações comerciais de NPK simples, contendo impurezas de micronutrientes, também eram eficientes, apresentando melhores resultados que os meios mais complexos para a germinação de orquídeas in vitro.

Park et al. (2002), ao avaliarem a micropropagação in vitro de quatro variedades de Phalaenopsis cultivadas no meio MS, além de verificarem resposta altamente significativa à adição de $\operatorname{BAP}\left(88,8 \mu \mathrm{mol} \mathrm{L}^{-1}\right) \mathrm{e} \operatorname{ANA}\left(5,4 \mu \mathrm{mol} \mathrm{L}^{-1}\right)$ ao meio de cultivo, com produção de 10 a 13 protocórmios por explante em 12 semanas, também observaram que o uso de Hyponex $^{\circledR}\left(1 \mathrm{~g} \mathrm{~L}^{-1}\right.$ de NPK 6,5-4,5-19 + $2 \mathrm{~g} \mathrm{~L}^{-1}$ de NPK 20-2020) como fonte de nutrientes promoveu resultados semelhantes aos encontrados com o meio MS.

Nessa mesma linha, Alam et al. (2002) verificaram que, na micropropagação de Dendrobium transparens Wall., melhores resultados em altura de planta, número de folhas e raízes e taxa de sobrevivência ex vitro foram obtidos com o uso do meio MS, em comparação com o meio Knudson C (Knudson, 1946) e os fertilizantes Hyponex ${ }^{\circledR} \mathrm{e} \mathrm{OKF}_{1}$. Todavia, o Hyponex ${ }^{\circledR}$, apesar de diferir estatisticamente, apresentou resultados próximos àqueles encontrados para o $\mathrm{MS}$ e muito superiores em relação aos meios $\mathrm{KC} \mathrm{e} \mathrm{OKF}_{1}$.

No cultivo de Cypripedium macranthos $\mathrm{Sw}$. em meio Hyponex $^{\circledR}\left(\mathrm{N}=65 \mathrm{~g} \mathrm{~kg}^{-1} ; \mathrm{P}=60 \mathrm{~g} \mathrm{~kg}^{-1}\right.$ e $\left.\mathrm{K}=190 \mathrm{~g} \mathrm{~kg}^{-1}\right)$ suplementado com peptona $\left(3 \mathrm{~g} \mathrm{~L}^{-1}\right)$, ANA $\left(10 \mu \mathrm{mol} \mathrm{L}^{-1}\right) \mathrm{e}$

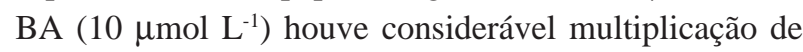
protocórmios anteriormente obtidos de sementes maduras. Cada protocórmio deu origem a 10 outras plântulas, as quais foram transferidas para meio livre de hormônios, enraizadas e posteriormente transplantadas para casa de vegetação, com $80 \%$ de sobrevivência (Shimura \& Koda, 2004).

Stancato \& Faria (1996), trabalhando com Laelia cinnabarina Bateman ex Lindl., in vitro, estudaram o efeito da exclusão de nutrientes do meio de cultivo. Para isso utilizaram a solução de Hoagland \& Arnon (1950) da seguinte forma: completa, menos micronutrientes e individualmente, excluindo-se: N, P, K, Ca, Mg e S. Além desses nutrientes, utilizou-se como tratamento adicional o meio MS, com a metade da concentração original de macronutrientes ( $\left.1 \frac{1}{2} \mathrm{MS}\right)$. Os resultados mostraram que a exclusão de $\mathrm{N}$ do meio foi a mais prejudicial, seguida por $\mathrm{S}, \mathrm{Ca}$ e $\mathrm{P}$ (não houve diferença entre os três últimos), $\mathrm{K}$ e micronutrientes (não diferiram entre si) $\mathrm{Mg}$ completa e $1 / 2 \mathrm{MS}$.

O objetivo deste trabalho foi avaliar a resposta de plântulas de orquídeas cultivadas in vitro a diferentes meios de cultivo e com a adição de fertilizantes NPK + micronutrientes em substituição aos meios de culturas tradicionais, como o MS.

\section{MATERIAL E MÉTODOS}

Para a realização deste ensaio foram utilizadas plântulas do híbrido Etibaia (Cattleya walkeriana $x$ C. loddigesii), provenientes de sementes com aproximadamente $0,5 \mathrm{~cm}$ de altura. Inicialmente, as plântulas foram cultivadas em meio Knudson C (Knudson, 1946), durante seis meses, no Laboratório de Cultura de Células e Tecidos Vegetais do Departamento de Fitotecnia da Universidade Federal de Viçosa, Minas Gerais.

Este ensaio foi constituído por um fatorial $(3 \times 5)+1$, sendo três meios de cultivo, cinco doses crescentes desses meios e um meio tradicional (Knudson C), com quatro repetições. Os meios de cultivo utilizados foram: meio Novais (MN) (Tabela 1); duas formulações do fertilizante Peters $^{\circledR}$ : NPK 10-30-20 + micro (em g kg-1, N 100, P 130,9, K 166,0, Mg 0,6; e, em mg kg-1 , B 68, Fe 500, Zn 25, Cu 36, Mn 250 e Mo 9) e NPK 30-10-10 + micro (em g kg ${ }^{-1}, \mathrm{~N} 300, \mathrm{P}$

Tabela 1. Composição dos meios de cultura de Knudson C e Novais (MN) para recultivo in vitro de plântulas do híbrido Etibaia (Cattleya walkeriana $x$ C. loddigesii), em suas concentrações-padrão, utilizadas como referencial

\begin{tabular}{|c|c|c|}
\hline \multirow[t]{2}{*}{ Composição } & Knudson C & MN \\
\hline & \multicolumn{2}{|c|}{$\mathrm{g} \mathrm{L}^{-1}$} \\
\hline Nitrato de cálcio & 1,00 & 1,00 \\
\hline Fosfato monobásico de amônio (MAP) & - & 0,50 \\
\hline Fosfato monobásico de potássio & 0,25 & - \\
\hline Sulfato de potássio & - & 0,25 \\
\hline Sulfato de magnésio & 0,25 & 0,25 \\
\hline \multirow[t]{2}{*}{ Sulfato de amônio } & 0,50 & - \\
\hline & \multicolumn{2}{|c|}{$\mathrm{mg} \mathrm{L}^{-1}$} \\
\hline Sulfato ferroso & 0,0250 & 0,0250 \\
\hline Sulfato de zinco & - & 0,0050 \\
\hline Sulfato de manganês & 0,0075 & 0,0075 \\
\hline \multirow[t]{2}{*}{ Ácido bórico } & - & 0,0050 \\
\hline & \multicolumn{2}{|c|}{$\mathrm{g} \mathrm{L}^{-1}$} \\
\hline Sacarose & 20,0 & 20,0 \\
\hline Ágar & 10,0 & 10,0 \\
\hline Carvão ativado & - & 2,0 \\
\hline Água de coco $(\mathrm{mL})$ & - & 200,0 \\
\hline
\end{tabular}


43,6, K 83,0, Mg 5; em mg kg-1 , B 68, Fe 500, Zn 22, Cu 36, Mn 250 e Mo 9); e o meio Knudson C como referencial (Tabela 1). Em todos os meios foram adicionados $20 \mathrm{~g} \mathrm{~L}^{-1}$ de sacarose, solidificados com $10 \mathrm{~g} \mathrm{~L}^{-1}$ de ágar $\left(\right.$ Merck $^{\circledR}$, Alemanha) e o pH ajustado a 5,7. Aos meios MN e Peters ${ }^{\circledR}$ foram acrescentados $2 \mathrm{~g} \mathrm{~L}^{-1}$ de carvão ativado e $200 \mathrm{ml} \mathrm{L}^{-1}$ de água de coco.

Foram utilizadas as seguintes concentrações de sais de cada meio: 0,$25 ; 0,50 ; 1,00 ; 1,75$ e $2,25 \mathrm{~g} \mathrm{~L}^{-1}$, exceto no Knudson C (2,0 $\left.\mathrm{g} \mathrm{L}^{-1}\right)$. A unidade experimental foi composta por um frasco de vidro de $320 \mathrm{~mL}$ contendo $35 \mathrm{~mL}$ de meio nutritivo, com cinco plântulas do híbrido Etibaia. Quando repicadas para os frascos com o respectivo tratamento, essas foram separadas individualmente e limpas do ágar aderido às raízes.

As condições da sala de crescimento foram mantidas constantes a $27 \pm 2{ }^{\circ} \mathrm{C}$, com $16 / 8 \mathrm{~h}$ luz/escuro e irradiância de $48 \mu \mathrm{mol} \mathrm{m} \mathrm{m}^{-2} \mathrm{~s}^{-1}$, fornecida por tubos fluorescentes Osram $^{\circledR}, 40 \mathrm{~W}$ luz do dia.

Ao final de seis meses foram avaliados: crescimento das plântulas quanto à produção de matérias fresca e seca de raízes e de parte aérea, comprimento e número de raízes, altura e número de unidades da parte aérea (formadas pelo limbo foliar mais pseudobulbo).

Os tecidos da parte aérea foram secos em estufa de circulação forçada de ar a $70{ }^{\circ} \mathrm{C}$, até peso constante, moídos e submetidos à digestão nítrico-perclórica para a determinação dos nutrientes. Os teores de $\mathrm{P}, \mathrm{K}, \mathrm{Ca}, \mathrm{Mg}, \mathrm{S}$, $\mathrm{Fe}, \mathrm{Mn}, \mathrm{B}$ e $\mathrm{Zn}$ foram detectados por espectrometria de emissão ótica em plasma induzido (ICP) e de N pelo método semimicro-Kjeldahl (Embrapa, 1999).

A análise de variância e os contrastes $\left(\mathrm{C}_{1}=\mathrm{K} v s \mathrm{MN}+\right.$ P 10-30-20 + P 30-10-10; $\mathrm{C}_{2}=\mathrm{MN}$ vs P 10-30-20 + P 30-10$10 ; \mathrm{C}_{3}=\mathrm{P} 10-30-20$ vs $\mathrm{P} 30-10-10 ; \mathrm{e}_{4}=\mathrm{K}$ vs média da dose 2,25 $\mathrm{g} \mathrm{L}^{-1}$ ) foram realizados com auxílio do programa SAEG 9.0, ajustando-se equações de regressão para as variáveis: produção de matéria fresca da parte aérea (MFPA), matéria fresca de raízes (MFR), matéria fresca total (MFT), relação raiz:parte aérea (RA/PA), número de raízes (NR), comprimento médio de raízes (CMR), unidades de parte aérea (UPA), comprimento médio das unidades de parte aérea (CMUPA), número de unidades de parte aérea maiores que $2 \mathrm{~cm}$ (UPA > 2) e teores de nutrientes na parte aérea (pseudobulbos e folhas) das plântulas como variáveis de doses dos fertilizantes dentro dos diferentes meios de cultivo.

\section{RESULTADOS E DISCUSSÃO}

A partir da análise dos contrastes observou-se maior produção de matéria fresca da parte aérea (MFPA) das plântulas por frasco com a utilização dos meios Novais $(\mathrm{MN})$ e fertilizantes Peters ${ }^{\circledR}$, não ocorrendo diferença significativa entre eles (Tabela 2). Comparando os efeitos da maior dose dos fertilizantes, 2,25 $\mathrm{g} \mathrm{L}^{-1}$, adicionada aos meios $\mathrm{MN}$ e Peters $^{\circledR}$ em relação ao meio Knudson C (2,0 $\left.\mathrm{g} \mathrm{L}^{-1}\right)$, percebe-se que a produção de MFPA foi menor ( $\mathrm{p}<0,01)$ com a utilização de Kudson C (Tabela 2). As equações obtidas com os resultados da produção de MFPA das plântulas para os fertilizantes Peters ${ }^{\circledR}$ foram lineares; para o meio MN, as respostas resultaram em um modelo cúbico, sendo as produtividades máximas estimadas iguais a 4,07; 3,70; e 3,11 g/frasco para MN, Peters ${ }^{\circledR}$ 10-30-20 e 30-10-10, respectivamente (Tabela 3).

Observaram-se diferenças significativas para a produção de matéria fresca de raízes (MFR) entre os diferentes meios, e nos $\mathrm{MN}$ e Peters ${ }^{\circledR}$ a produção de raízes foi maior que no Knudson C (Tabela 2). O Peters ${ }^{\circledR}$ resultou em maior produção de MFR quando comparado com o MN, porém entre as duas formulações de Peters ${ }^{\circledR}$ as diferenças não foram significativas. Apenas no meio com Peters ${ }^{\circledR} 30-10-10$ observou-se incremento na produção de MFR com o aumento das doses (Tabela 3 ).

Em termos de produção de matéria fresca total (MFT), nos meios MN e Peters ${ }^{\circledR}$ as respostas foram lineares ao efeito de doses, sendo as produtividades máximas estimadas iguais a: 8,94; 9,65; e 9,18 g/frasco, para o MN, Peters ${ }^{\circledR} 10-30-20$ e 30-10-10, respectivamente (Tabela 3). Para a média das doses, as formulações do fertilizante Peters ${ }^{\circledR}$ apresentaram produção significativamente maior que no MN (Tabela 2). Resultados semelhantes foram obtidos por Stancato et al. (2008) ao avaliarem a produção de matéria seca de plântulas de Laelia longipes Rchb. f. Esses autores verificaram que no meio Knudson $\mathrm{C}$ a produção de matéria seca foi $46 \%$ menor que a obtida em meio com formulação NPK 10-30-20.

A relação raiz/parte aérea (R/PA) foi menor no meio Knudson; entretanto, comparando-se apenas o meio Knudson $\mathrm{C}$ com os demais, na dose 2,25 $\mathrm{g} \mathrm{L}^{-1}$ a diferença para esse contraste não foi significativa (Tabela 2). A R/ PA como variável das doses do fertilizante Peters ${ }^{\circledR} 30-10$ 10 foi linear, com inclinação negativa, observando-se pequenas diferenças na relação R/PA entre doses (Tabela 3). Por outro lado, em MN e Peters ${ }^{\circledR} 10-30-20$ os valores foram altos para essa relação, em doses baixas do Peters ${ }^{\circledR}$, e decréscimo curvilinear com o aumento de suas doses. Essa diferença no comportamento da relação R/PA para Peters ${ }^{\circledR} 30-10-10$ pode ser uma resposta da planta à fonte de $\mathrm{N}$ no fertilizante (Cunha et al., 2011). Segundo Majerowicz \& Kerbauy (2002), para plantas do gênero Catasetum as fontes nítricas estimularam a produção de raízes. Os autores consideraram a possibilidade de fontes amoniacais restringirem o crescimento da parte aérea dessas plantas. Por outro lado, Marschner (1995) colocou que a fertilização nitrogenada promove menor relação R/ $\mathrm{PA}$, e os efeitos na diminuição da R/PA são mais frequentes com fontes amoniacais. 
O número de raízes (NR) por frasco não diferiu quando comparados o meio Knudson $\mathrm{C}$ e a média dos demais. Entretanto, diferenças significativas ocorreram entre o MN e os meios com as formulações de Peters ${ }^{\circledR}$, observando-se maior NR por frasco com o fertilizante 10-30-20 (Tabelas 2 e 3). Por outro lado, o comprimento médio de raízes (CMR) foi menor em Knudson $\mathrm{C}$ tanto quando se comparam as médias dos tratamentos como em relação aos tratamentos (meios) correspondentes à dose 2,25 $\mathrm{g} \mathrm{L}^{-1}$. Rego-Oliveira \& Faria (2005) verificaram, ao avaliarem o crescimento de Catasetum fimbriatum (E. Morren) Lindl. \& Paxton empregando diferentes meios de cultivo, entre eles Knudson $\mathrm{C}$ e a formulação NPK 10-30-20, que o NR foi significativamente maior com a formulação 10-30-20. Todavia, com relação ao CMR, esses autores não encontraram diferença estatística entre os dois meios, resultado oposto ao obtido no presente trabalho.

O número de unidades da parte aérea (UPA) foi, em média, maior com o uso do meio MN e dos fertilizantes Peters ${ }^{\circledR}$ em relação ao meio Knudson C. O efeito de doses foi significativo, apresentando aumento no número de UPA; entretanto, não houve, para média das doses, diferenças significativas entre o $\mathrm{MN}$ e os meios com as formulações Peters ${ }^{\circledR}$ (Tabela 2).

Para o comprimento médio de unidades da parte aérea (CMUPA) foram encontrados valores significativamente maiores para o meio Knudson $\mathrm{C}$ em relação aos demais (Tabelas 2 e 3). No meio MN, os valores de CMUPA foram menores quando comparados àqueles das duas formulações Peters ${ }^{\circledR}$; entre essas formulações não foi encontrada diferença significativa.

A literatura salienta a importância de que as vitro-plantas de orquídeas alcancem tamanho adequado (acima de $2 \mathrm{~cm}$ de altura e com raízes) para serem retiradas dos fras- cos de cultivo, de modo a otimizar sua adaptação às condições de cultivo ex vitro. Para esta variável, a diferença significativa ( $p>0,001)$ encontrada entre o meio Knudson $\mathrm{C}$ com a média dos demais meios, na dose $2,25 \mathrm{~g} \mathrm{~L}^{-1}$, aparentemente reflete a maior concentração de nutrientes nesses meios (Tabela 2).

Os teores de $\mathrm{N}$ na parte aérea das plântulas diferiram significativamente ( $\mathrm{p}>0,001)$ entre $\mathrm{MN}$, as duas formulações de Peters ${ }^{\circledR}$ e o meio Knudson (Tabela 4). Todavia, o teor médio encontrado em Peters ${ }^{\circledR}$ 30-10-10 foi superior àquele obtido para Peters ${ }^{\circledR} 10-30-20$ e MN, com resposta linear para doses, tendo as curvas apresentado comportamentos semelhantes para MN e Peters ${ }^{\circledR}$ 10-30-20 (Tabela 5). Os teores máximos de $\mathrm{N}$ para $\mathrm{MN}$, Peters ${ }^{\circledR} 10-30-20 \mathrm{e}$ 30-10-10 foram, respectivamente, 16,3; 15,7; e 27,6 $\mathrm{g} \mathrm{kg}^{-1}$. Para Majerowicz et al. (2000), o teor de N na parte aérea de orquídeas é dependente da forma de $\mathrm{N}$ predominante no meio, o que pode estar interferindo nos resultados encontrados.

Diferenças significativas entre os teores de $\mathrm{P}$ nas plântulas foram encontradas entre as formulações Peters ${ }^{\circledR}$ ( $p$ > 0,001) e na comparação entre o meio Knudson C e a média da dose $2,25 \mathrm{~g} \mathrm{~kg}^{-1}(\mathrm{p}>0,01)$ (Tabela 4). Comportamento linear foi observado com a utilização de Peters ${ }^{\circledR} 10$ 30-20 e MN, com teores máximos de P de 8,2 e 7,0 g kg-1 nas plântulas, valores esses elevados se comparados com os obtidos em Peters ${ }^{\circledR}$ 30-10-10, em média 3,3 g kg-1 $^{-1}$ (Tabela 5). Rodrigues et al. (2012) observou a mesma tendência para Cattleya walkeriana Gardner. Jones Jr. et al. (1991) consideram que os teores adequados de $\mathrm{P}$, para Cattleya, encontram-se na faixa de 1,0 a 7,5 $\mathrm{g} \mathrm{kg}^{-1}$.

Apenas entre as formulações de Peters ${ }^{\circledR}$ não foi detectada diferença estatística entre os teores de $\mathrm{K}$ nas plântulas do híbrido Etibaia (Tabela 4). A utilização de doses crescentes de Peters ${ }^{\circledR}$ 30-10-10 resultou em uma

Tabela 2. Contrastes médios para as variáveis: massa de matéria fresca da parte aérea (MFPA), de matéria fresca de raízes (MFR), de matéria fresca total (MFT), relação raiz/parte aérea (R/PA), número de raízes por frasco (NR), unidades de parte aérea por frasco (UPA), comprimento médio de raízes (CMR), comprimento médio das unidades de parte aérea (CMUPA) e número de UPA maiores que $2 \mathrm{~cm}$ por frasco (UPA > 2) de plântulas do híbrido Etibaia (Cattleya walkeriana $x$ C. loddigesii) submetidas aos diferentes meios de cultivo

\begin{tabular}{|c|c|c|c|c|c|c|c|c|c|}
\hline \multirow[t]{2}{*}{ Contraste $^{(1)}$} & MFPA & MFR & MFT & \multirow[t]{2}{*}{$\mathbf{R} / \mathbf{P A}$} & \multirow[t]{2}{*}{ NR } & \multirow[t]{2}{*}{ UPA } & CMR & CMUPA & \multirow[t]{2}{*}{ UPA $>2$} \\
\hline & & $\mathrm{g} /$ frasco & & & & & \multicolumn{2}{|c|}{$\mathrm{cm} /$ frasco } & \\
\hline $\mathrm{C}_{1}$ & $0,87 * *$ & $2,53 * *$ & $3,40 * * *$ & $0,92^{\circ}$ & $6,05^{\mathrm{ns}}$ & $3,98 *$ & $2,03^{*}$ & $-0,35^{\circ}$ & $0,77^{\mathrm{ns}}$ \\
\hline $\mathrm{C}_{2}$ & $0,02^{\mathrm{ns}}$ & $0,91 *$ & $0,93^{\circ}$ & $-0,07^{\mathrm{ns}}$ & $7,80 * *$ & $0,65^{\mathrm{ns}}$ & $0,39^{\mathrm{ns}}$ & $0,35 * * *$ & $2,80 * *$ \\
\hline $\mathrm{C}_{3}$ & $0,16^{\mathrm{ns}}$ & $-0,63^{\mathrm{ns}}$ & $-0,47^{\mathrm{ns}}$ & $-1,34 * * *$ & $8,10^{*}$ & $3,40 * *$ & $-1,40 * *$ & $-0,09^{\text {ns }}$ & $0,70^{\mathrm{ns}}$ \\
\hline $\mathrm{C}_{4}$ & $2,16^{* * *}$ & $2,16 * * *$ & $5,18 * * *$ & $-0,54^{\mathrm{ns}}$ & $8,75^{\mathrm{ns}}$ & $7,67 * *$ & $1,23 * *$ & $0,20^{\mathrm{ns}}$ & $6,42 * * *$ \\
\hline
\end{tabular}

${ }^{\circ}, *, * *, \mathrm{e}^{* * *}$, significativos pelo teste $\mathrm{F}$ a $10 ; 5,0 ; 1,0 ;$ e $0,1 \%$, respectivamente.

$\mathrm{C}_{1}=\mathrm{K}$ vs $\mathrm{MN}+\mathrm{P} 10-30-20+\mathrm{P} 30-10-10, \mathrm{C}_{2}=\mathrm{MN}$ vs $\mathrm{P} 10-30-20+\mathrm{P} 30-10-10 ; \mathrm{C}_{3}=\mathrm{P} 10-30-20$ vs $\mathrm{P}$ 30-10-10; $\mathrm{C}_{4}=\mathrm{K}$ vs Média da dose 2,25 $\mathrm{g} \mathrm{L}^{-1}$. K = Knudson; MN = Meio Novais; P 10-30-20 e P 30-10-10 = Fertilizantes Peters ${ }^{\circledR}$ em suas formulações NPK 10-30-20 e 3010-10, respectivamente.

(1) Os três primeiros contrastes comparam a resposta média das doses de cada meio e o quarto compara o Knudson C com a reposta para a última dose $\left(2,25 \mathrm{~g} \mathrm{~L}^{-1}\right)$ dos demais meios. Valores positivos indicam que o primeiro componente do contraste é menor do que o segundo componente da comparação.

Rev. Ceres, Viçosa, v. 59, n.1, p. 1-8, jan/fev, 2012 
Tabela 3. Equações de regressão ajustadas para produção de matéria fresca da parte aérea (MFPA), raízes (MFR) e total (MFT); relação raiz/parte aérea (R/PA), número de raízes (NR), unidades de parte aérea (UPA), comprimento médio de raízes (CMR) comprimento médio de UPA (CMUPA), número de UPA maiores que $2 \mathrm{~cm}$ (UPA > 2) e de plântulas do híbrido Etibaia (Cattleya walkeriana $x$ C. loddigesii) cultivadas in vitro como variáveis das doses dos diferentes meios de cultivo

\begin{tabular}{|c|c|c|}
\hline Meio & Equação & $\mathbf{R}^{2}$ \\
\hline \multicolumn{3}{|c|}{ MFPA (g/frasco) } \\
\hline Knudson C (2 g) & $\mathrm{y}=1,29$ & \\
\hline Meio Novais (MN) & $\hat{y}=1,755-5,055^{*} x+6,563 * * x^{2}-1,730 * * x^{3}$ & 0,978 \\
\hline Peters ${ }^{\circledR} 10-30-20$ & $\hat{\mathrm{y}}=0,385+1,477 * * * \mathrm{x}$ & 0,992 \\
\hline Peters $^{\circledR} 30-10-10$ & $\hat{\mathrm{y}}=1,331+0,792 * * * \mathrm{x}$ & 0,898 \\
\hline \multicolumn{3}{|c|}{ MFR (g/frasco) } \\
\hline Knudson C (2 g) & $y=2,49$ & \\
\hline Meio Novais (MN) & $\mathrm{w}=\bar{y}=4,0$ & - \\
\hline Peters $^{\circledR} 10-30-20$ & $\mathrm{w}=\overline{\mathrm{y}}=5,6$ & - \\
\hline Peters $^{\circledR} 30-10-10$ & $\mathrm{w}=3,911+0,958 * \mathrm{x}$ & 0,893 \\
\hline \multicolumn{3}{|c|}{ MFT (g/frasco) } \\
\hline Knudson C (2 g) & $\mathrm{y}=3,78$ & \\
\hline Meio Novais (MN) & $\hat{y}=4,067+2,168 * * * x$ & 0,878 \\
\hline Peters $^{\circledR} 10-30-20$ & $\hat{\mathrm{y}}=5,718+1,746^{* *} \mathrm{x}$ & 0,912 \\
\hline Peters $^{\circledR} 30-10-10$ & $\hat{\mathrm{y}}=5,242+1,751 * * \mathrm{x}$ & 0,928 \\
\hline \multicolumn{3}{|c|}{$\mathbf{R} / \mathbf{P A}$} \\
\hline Knudson C (2 g) & $\mathrm{y}=2,18$ & \\
\hline Meio Novais (MN) & $\hat{y}=6,557-4,479 * * * x+0,920 * x^{2}$ & 0,992 \\
\hline Peters ${ }^{\circledR} 10-30-20$ & $\hat{y}=14,196-16,942 * * * x^{0,5}+5,729 * x$ & 0,989 \\
\hline Peters $^{\circledR} 30-10-10$ & $\hat{y}=2,988-0,513^{\circ} x$ & 0,630 \\
\hline \multicolumn{3}{|c|}{ NR (unidades/frasco) } \\
\hline Knudson C (2 g) & $\mathrm{y}=45,0$ & \\
\hline Meio Novais (MN) & $\hat{y}=58,748-86,911^{\circ} x+98,076^{*} x^{2}-27,408^{*} x^{3}$ & 0,808 \\
\hline Peters $^{\circledR} 10-30-20$ & $\hat{\mathrm{y}}=17,032+54,866 * * * \mathrm{x}-16,174 * * \mathrm{x}^{2}$ & 0,896 \\
\hline Peters $^{\circledR} 30-10-10$ & $\hat{y}=\bar{y}=57,7$ & - \\
\hline \multicolumn{3}{|c|}{ CMR (cm) } \\
\hline Knudson C (2 g) & $y=3,22$ & \\
\hline Meio Novais (MN) & $\hat{\mathrm{y}}=4,636+6,713 * * * \mathrm{x}-8,001 * * * \mathrm{x}^{2}+2,164 * * * \mathrm{x}^{3}$ & 0,995 \\
\hline Peters ${ }^{\circledR} 10-30-20$ & $\hat{y}=9,940-5,809 * * x+1,495 * x^{2}$ & 0,973 \\
\hline Peters $^{\circledR} 30-10-10$ & $\hat{y}=\bar{y}=4,7$ & - \\
\hline \multicolumn{3}{|c|}{ UPA (unidades/frasco) } \\
\hline Knudson C (2 g) & $y=14,75$ & \\
\hline Meio Novais (MN) & $\hat{y}=18,569-28,874^{n s} x+35,629 * x^{2}-9,590 * x^{3}$ & 0,958 \\
\hline Peters $^{\circledR} 10-30-20$ & $\hat{\mathrm{y}}=3,287+24,909 * * * \mathrm{x}-7,779 * * \mathrm{x}^{2}$ & 0,962 \\
\hline Peters $^{\circledR} 30-10-10$ & $\hat{y}=16,650+3,478 * * x$ & 0,756 \\
\hline \multicolumn{3}{|c|}{ CMUPA $(\mathbf{c m})$} \\
\hline Knudson C (2 g) & $y=2,69$ & \\
\hline Meio Novais (MN) & $\hat{\mathrm{y}}=1,219+1,407 * * \mathrm{x}-0,386^{\circ} \mathrm{x}^{2}$ & 0,977 \\
\hline Peters $^{\circledR} 10-30-20$ & $\hat{y}=0,824+3,595^{*} x-2,634^{\circ} x^{2}+0,704^{\circ} x^{3}$ & 1,000 \\
\hline Peters $^{\circledR} 30-10-10$ & $\hat{y}=2,103+0,268 * x$ & 0,883 \\
\hline \multicolumn{3}{|c|}{$\mathrm{UPA}>2(\mathrm{~cm})$} \\
\hline Knudson C (2 g) & $y=10,25$ & \\
\hline Meio Novais (MN) & $\hat{\mathrm{y}}=0,952+7,128 * * * \mathrm{x}$ & 0,966 \\
\hline Peters $^{\circledR} 10-30-20$ & $\hat{\mathrm{y}}=-2,334+21,17 * * * \mathrm{x}-5,516 * * \mathrm{x}^{2}$ & 0,997 \\
\hline Peters $^{\circledR} 30-10-10$ & $\hat{\mathrm{y}}=7,634+4,057 * * * \mathrm{x}$ & 0,783 \\
\hline
\end{tabular}

$\circ, *, * * \mathrm{e}^{* * *}$, significativos pelo teste $\mathrm{F}$ a $10 ; 5,0 ; 1,0$; e $0,1 \%$, respectivamente. 
curva raiz quadrada para $\mathrm{K}$ (Tabela 5); para os outros dois casos, MN e Peters ${ }^{\circledR} 10-30-20$, o aumento do teor de K na parte aérea foi linear. Contudo, para o crescimento radicular observou-se redução no CMR com o aumento da concentração de sais nos meios, o que poderia estar relacionado à concentração de K no meio. Figueiredo et al. (2008) atribuíram ao efeito tóxico do excesso de $\mathrm{K}_{2} \mathrm{SO}_{4}$, adicionado ao meio de cultura, a

Tabela 4. Contrastes médios para os teores de macro e micronutrientes na parte aérea de plântulas do híbrido Etibaia (Cattleya walkeriana $x$ C. loddigesii) cultivadas in vitro como variáveis das doses dos diferentes meios de cultivo

\begin{tabular}{|c|c|c|c|c|c|c|c|c|c|c|}
\hline \multirow[t]{2}{*}{ Contraste } & $\mathbf{N}$ & $\mathbf{P}$ & $\mathbf{K}$ & $\mathbf{C a}$ & Mg & $\mathbf{S}$ & $\mathbf{F e}$ & Mn & B & Zn \\
\hline & \multicolumn{6}{|c|}{$\mathrm{g} \mathrm{kg}^{-1}$} & \multicolumn{4}{|c|}{$\mathrm{mg} \mathrm{kg}^{-1}$} \\
\hline $\mathrm{C}_{1}$ & $-3,33 * * *$ & $-0,08^{\text {ns }}$ & $7,20 * * *$ & $-2,16 * *$ & $-0,10^{\mathrm{ns}}$ & $-1,68 * * *$ & $-9^{\mathrm{ns}}$ & $-18^{\text {ns }}$ & $-24^{\mathrm{ns}}$ & $7^{\mathrm{ns}}$ \\
\hline $\mathrm{C}_{2}$ & $1,62 * * *$ & $-0,08^{\mathrm{ns}}$ & $4,52 * * *$ & $-1,93 * * *$ & $0,08^{\mathrm{ns}}$ & $-0,72 * * *$ & $-4^{\mathrm{ns}}$ & $-7^{\mathrm{ns}}$ & $2^{\mathrm{ns}}$ & $-14 * * *$ \\
\hline $\mathrm{C}_{3}$ & $3,23 * * *$ & $-0,86 * * *$ & $-0,09^{\mathrm{ns}}$ & $-0,16^{\mathrm{ns}}$ & $-0,27 * *$ & $-0,41 * *$ & $-4^{\mathrm{ns}}$ & $8^{\text {ns }}$ & $-2^{\mathrm{ns}}$ & $-3^{\mathrm{ns}}$ \\
\hline $\mathrm{C}_{4}$ & $-0,22^{\mathrm{ns}}$ & $0,95 * *$ & $9,79 * * *$ & $-2,38 * *$ & $0,06^{\mathrm{ns}}$ & $-1,34 * * *$ & $-17^{\mathrm{ns}}$ & $-17^{\text {ns }}$ & $-27^{\mathrm{ns}}$ & $9^{\circ}$ \\
\hline
\end{tabular}

o, *, ** e ***, significativos pelo teste $\mathrm{F}$ a $10 ; 5,0 ; 1,0 ;$ e $0,1 \%$, respectivamente.

$\mathrm{C}_{1}=\mathrm{K}$ vs $\mathrm{MN}+\mathrm{P} 10-30-20+\mathrm{P}$ 30-10-10, $\mathrm{C}_{2}=\mathrm{MN}$ vs $\mathrm{P} 10-30-20+\mathrm{P} 30-10-10 ; \mathrm{C}_{3}=\mathrm{P} 10-30-20$ vs $\mathrm{P}$ 30-10-10; $\mathrm{C}_{4}=\mathrm{K}$ vs Média da dose $2,25 \mathrm{~g} \mathrm{~L}^{-1}$.

$\mathrm{K}=$ Knudson, $\mathrm{MN}=$ Meio Novais, $\mathrm{P}$ 10-30-20 e P 30-10-10 = Fertilizantes Peters ${ }^{\circledR}$ em suas formulações NPK 10-30-20 e 30-10-10, respectivamente.

Tabela 5. Equações de regressão ajustadas para os teores de macronutrientes $\left(\mathrm{g} \mathrm{kg}^{-1}\right)$ na parte aérea de plântulas do híbrido Etibaia (Cattleya walkeriana $x$ C. loddigesii) cultivadas in vitro como variáveis das doses dos diferentes meios de cultivo

\begin{tabular}{|c|c|c|}
\hline Meio & Equação & $\mathbf{R}^{2}$ \\
\hline \multicolumn{3}{|c|}{$\mathbf{N}\left(\mathrm{g} \mathrm{kg}^{-1}\right)$} \\
\hline Knudson C (2 g) & $y=20,17$ & \\
\hline Meio Novais (MN) & $\hat{y}=6,210+4,470 * * * x$ & 0,924 \\
\hline Peters $^{\circledast} 10-30-20$ & $\hat{\mathrm{y}}=6,972+3,826^{* * *} \mathrm{x}$ & 0,911 \\
\hline Peters $^{\circledR} 30-10-10$ & $\hat{\mathrm{y}}=7,576+8,920 * * * x$ & 0,982 \\
\hline \multicolumn{3}{|c|}{$\mathbf{P}\left(\mathrm{g} \mathrm{kg}^{-1}\right)$} \\
\hline Knudson C (2 g) & $\mathrm{y}=4,36$ & \\
\hline Meio Novais (MN) & $\hat{y}=1,426+2,498 * * * x$ & 0,945 \\
\hline Peters $^{\circledR} 10-30-20$ & $\hat{y}=1,697+2,872 * * * x$ & 0,996 \\
\hline Peters ${ }^{\circledR} 30-10-10$ & $\hat{\mathrm{y}}=\overline{\mathrm{y}}=3,3$ & \\
\hline \multicolumn{3}{|c|}{$\mathrm{K}\left(\mathrm{g} \mathrm{kg}^{-1}\right)$} \\
\hline Knudson C (2 g) & $\mathrm{y}=13,02$ & \\
\hline Meio Novais (MN) & $\hat{\mathrm{y}}=14,755+5,200 * * \mathrm{x}$ & 0,931 \\
\hline Peters $^{\circledR} 10-30-20$ & $\hat{\mathrm{y}}=16,478+12,224 * * * \mathrm{x}$ & 0,800 \\
\hline Peters $^{\circledR} 30-10-10$ & $\hat{y}=3,014+56,888^{*} x^{0,5}-25,996 * x$ & 0,780 \\
\hline \multicolumn{3}{|c|}{$\mathrm{Ca}\left(\mathrm{g} \mathrm{kg}^{-1}\right)$} \\
\hline Knudson C (2 g) & $y=13,43$ & \\
\hline Meio Novais (MN) & $\hat{y}=20,790-24,920 * * x^{0,5}+13,877 * * x$ & 0,828 \\
\hline Peters $^{\circledR} 10-30-20$ & $\hat{y}=9,728-1,52563 * x$ & 0,5497 \\
\hline Peters $^{\circledR} 30-10-10$ & $\hat{\mathrm{y}}=\overline{\mathrm{y}}=7,7$ & - \\
\hline \multicolumn{3}{|c|}{$\operatorname{Mg}\left(\mathrm{g} \mathrm{kg}^{-1}\right)$} \\
\hline Knudson C (2 g) & $\mathrm{y}=1,90$ & \\
\hline Meio Novais (MN) & $\hat{y}=1,154+0,389 * * x$ & 0,758 \\
\hline Peters $^{\circledR} 10-30-20$ & $\hat{\mathrm{y}}=1,124+0,789 * * * \mathrm{x}$ & 0,887 \\
\hline Peters $^{\circledR} 30-10-10$ & $\hat{y}=-0,056+3,903^{*} x^{0,5}-2,075^{*} x$ & 0,934 \\
\hline \multicolumn{3}{|c|}{$\mathrm{S}\left(\mathrm{g} \mathrm{kg}^{-1}\right)$} \\
\hline Knudson C (2 g) & $y=5,25$ & \\
\hline Meio Novais (MN) & $\hat{\mathrm{y}}=4,937-8,19 * \mathrm{x}^{0,5}+5,355^{*} * \mathrm{x}$ & 0,995 \\
\hline Peters $^{\circledR} 10-30-20$ & $\hat{\mathrm{y}}=\overline{\mathrm{y}}=1,8$ & - \\
\hline Peters $^{\circledR} 30-10-10$ & $\hat{\mathrm{y}}=\overline{\mathrm{y}}=1,0$ & - \\
\hline
\end{tabular}

$* * *, * *, * \mathrm{e}^{\mathrm{o}}$, significativos pelo teste $\mathrm{F}$ a 0,$1 ; 1,0 ; 5,0 ;$ e $10 \%$, respectivamente.

Rev. Ceres, Viçosa, v. 59, n.1, p. 1-8, jan/fev, 2012 
redução no crescimento radicular de plântulas de Cattleya loddigesii Lindl.

Os teores de $\mathrm{Ca}$ foram menores na parte aérea das plântulas que receberam os fertilizantes Peters ${ }^{\circledR}$, tendo entre esses, na formulação 10-30-20, obtido resposta linear decrescente com o aumento da dose (Tabelas 4 e 5). De modo geral, os teores de $\mathrm{Ca}$ encontrados na parte aérea dessas plântulas são considerados adequados (6$20 \mathrm{~g} \mathrm{~kg}^{-1}$ ) de acordo com a literatura (Jones Jr. et al., 1991; Novais \& Rodrigues, 2004), sendo o Ca disponibilizado pela água de coco adicionada ao meio que, proporcionalmente, contém um terço do teor de $\mathrm{Ca}$ do $\mathrm{MN}$ ou Knudson C (George, 1993). Por outro lado, o efeito de dose no caso do MN resultou em teores maiores quando comparado ao Peters ${ }^{\circledR}$. As limitações do Peters ${ }^{\circledR}$, provavelmente, serão maiores nas fórmulas ricas em $\mathrm{P}$, tendo em vista sua incompatibilidade com Ca (precipitação). Nesse caso, problemas com deficiência de Ca deverão ser mais acentuados.

Para o Mg, maior teor foi observado na parte aérea das plântulas cultivadas no meio contendo Peters ${ }^{\circledR} 10-30-20$, com resposta linear ao aumento da dose do fertilizante no meio de cultivo; resultado semelhante foi encontrado para MN (Tabela 5). Já os teores de Mg encontrados para o Peters ${ }^{\circledR}$ 30-10-10 apresentaram resposta definida por um modelo raiz quadrada, no qual os teores começaram a ter decréscimo em seu valor a partir $0,88 \mathrm{~g} \mathrm{~L}^{-1}$ de fertilizante (Tabela 5).
Como já relatado, outra carência dos fertilizantes Peters ${ }^{\circledR}$ diz respeito a $\mathrm{S}$, e neste trabalho os teores de $\mathrm{S}$ não variaram com a dose desse fertilizante no meio, apresentando valores baixos quando comparado com o teor encontrado com o uso de MN (Tabela 4). Os teores de S encontrados com o meio Knudson $\mathrm{C}$ foram superiores quando comparados com os fertilizantes Peters ${ }^{\circledR}$. Tanto o meio Knudson $\mathrm{C}$ quanto o $\mathrm{MN}$ apresentam $\mathrm{S}$ em sua composição (Tabela 1), propiciando o resultado encontrado.

Os teores de macronutrientes nos meios Knudson C e MN são semelhantes (Tabela 1); entretanto, quando esses são comparados com os fertilizantes Peters ${ }^{\circledR}$ percebem-se grandes diferenças (ver concentração de nutrientes das formulações em Material e Métodos). Os teores de $\mathrm{N}$ e $\mathrm{Mg}$ no Peters $^{\circledR}$ 30-10-10 são três e cinco vezes, respectivamente, maiores do que aqueles no Knudson e MN; no Peters ${ }^{\circledR} 10-30-20$, os teores de P e K foram aproximadamente três vezes maiores neste último, sendo que em suas garantias o fabricante não inclui, no caso destas duas formulações, Ca e S.

Em média, os teores de Fe não apresentaram diferenças significativas entre os meios, tendo apenas para o Peters ${ }^{\circledR}$ 30-10-10 sido possível ajustar uma equação linear e decrescente (Tabela 6) indicando diluição do teor de Fe na planta em razão do maior crescimento (Tabelas 4 e 6). Tendência semelhante foi observada com os teores de Mn, não ocorrendo diferenças significativas entre os tratamentos (Tabela 4). Os dois nutrientes estão dentro da

Tabela 6. Equações de regressão ajustadas para os teores de micronutrientes $\left(\mathrm{mg} \mathrm{kg}^{-1}\right)$ na parte aérea de plântulas do híbrido Etibaia (Cattleya walkeriana $x$ C. loddigesii) cultivadas in vitro como variáveis das doses dos diferentes meios de cultivo

\begin{tabular}{|c|c|c|}
\hline Meio & Equação & $\mathbf{R}^{2}$ \\
\hline \multicolumn{3}{|c|}{$\mathrm{Fe}\left(\mathrm{mg} \mathrm{kg}^{-1}\right)$} \\
\hline Knudson C (2 g) & $y=109,15$ & \\
\hline Meio Novais (MN) & $\hat{y}=\bar{y}=96$ & - \\
\hline Peters ${ }^{\circledR} 10-30-20$ & $\hat{\mathrm{y}}=\overline{\mathrm{y}}=92$ & - \\
\hline Peters $^{\circledast} 30-10-10$ & $\hat{y}=109,749-22,473^{\circ} x$ & 0,845 \\
\hline \multicolumn{3}{|c|}{$\operatorname{Mn}\left(\mathrm{mg} \mathrm{kg}^{-1}\right)$} \\
\hline Knudson C (2 g) & $y=226,74$ & \\
\hline Meio Novais (MN) & $\hat{y}=\bar{y}=200$ & - \\
\hline Peters ${ }^{\circledR} 10-30-20$ & $\widehat{\hat{y}}=\overline{\mathrm{y}}=178$ & - \\
\hline Peters ${ }^{\circledR} 30-10-10$ & $\hat{y}=6,275+415,375^{\circ} x^{0,5}-200,575^{\circ} x$ & 0,693 \\
\hline \multicolumn{3}{|c|}{ B $\left(\mathrm{mg} \mathrm{kg}^{-1}\right)$} \\
\hline Knudson C (2 g) & $y=156,78$ & \\
\hline Meio Novais (MN) & $\hat{y}=249,297-307,542^{\circ} x^{0,5}+144,088^{\circ} x$ & 0,887 \\
\hline Peters ${ }^{\circledR} 10-30-20$ & $\hat{\mathrm{y}}=\overline{\mathrm{y}}=112$ & \\
\hline Peters $^{\circledR} 30-10-10$ & $\hat{y}=-60,190+381,503 * x^{0,5}-187,992 * x$ & 0,846 \\
\hline \multicolumn{3}{|c|}{$\mathrm{Zn}\left(\mathrm{mg} \mathrm{kg}^{-1}\right)$} \\
\hline Knudson C (2 g) & $y=26,04$ & \\
\hline Meio Novais (MN) & $\hat{y}=42,31+14,26 * x$ & 0,75 \\
\hline Peters ${ }^{\circledR} 10-30-20$ & $\hat{\mathrm{y}}=\overline{\mathrm{y}}=34$ & \\
\hline Peters ${ }^{\circledR} 30-10-10$ & $\hat{\mathrm{y}}=\overline{\mathrm{y}}=29$ & \\
\hline
\end{tabular}


faixa considerada suficiente por Jones Jr. et al. (1991), de 50-200 e 40-200 mg kg-1, respectivamente, para Fe e Mn.

Os teores de B na planta são muito altos (Tabela 4) quando comparados aos teores adequados para plantas de orquídeas ex vitro (25-75 mg kg-1 - Jones Jr. et al., 1991), sendo que, em média, não houve diferença significativa entre os fertilizantes Peters ${ }^{\circledR}$ e MN (Tabela 4).

Para os teores de $\mathrm{Zn}$ foi possível ajustar um modelo apenas para MN, observando-se tendência linear com as doses crescentes desse meio, tendo na média das doses ele apresentado teores bem maiores do que aqueles encontrados com os demais tratamentos (Tabelas 4 e 6).

Os teores de nutrientes em Knudson C e MN são semelhantes, exceto para $\mathrm{Zn}$ e B, que não fazem parte do primeiro (Tabela 1). Comparando os teores de micronutrientes entre os meios Knudson C, MN e os fertilizantes Peters ${ }^{\circledR}$, percebe-se que eles são bem maiores nos dois primeiros. Ferro e Mn apresentam, respectivamente, teores seis e quatro vezes maiores do que em Knudson $\mathrm{C}$ e MN em relação ao Peters ${ }^{\circledR}$, e para Zn e B a diferença é ainda maior na comparação entre $\mathrm{MN}$ e os Peters ${ }^{\circledR}$, tendo os teores no primeiro sido 39 vezes maiores, respectivamente (ver Material e Métodos). Essa comparação é necessária, tendo em vista que a resposta (teores no tecido vegetal) a esses diferentes teores nos fertilizantes foi significativa ( $\mathrm{p}>0,001)$ apenas para $\mathrm{Zn}$, mostrando que os teores dos demais nutrientes nas plântulas não variaram mesmo na presença de teores mais elevados no meio MN (Tabela 1) em relação aos fertilizantes Peters ${ }^{\circledR}$.

\section{CONCLUSÕES}

A matéria fresca total de plântulas do híbrido Etibaia (Cattleya walkeriana x C. loddigesii) aumenta linearmente com o aumento da dose nos meios MN e Peters ${ }^{\circledR}$.

A utilização dos fertilizantes Peters ${ }^{\circledR}$ resulta em maior produção de matéria fresca de plântulas do híbrido do que os meios Knudson C e MN para a média das doses.

$\mathrm{O}$ meio $\mathrm{MN}$ apresenta respostas satisfatórias, com maior produção da parte aérea, sendo melhor alternativa aos atuais meios de cultivo, como o Knudson C.

\section{AGRADECIMENTOS}

Os autores agradecem à Fundação de Amparo à Pesquisa do Estado de Minas Gerais - FAPEMIG, pela concessão de bolsa de pós-doutoramento à Dra. Ecila Mercês de Albuquerque Villani.

\section{REFERÊNCIAS}

Alam MK, Rashid MH, Hossain MS, Salam MA \& Rouf MA (2002) In vitro seed propagation of dendrobium (Dendrobium transparens) orchid as influenced by different media. Biotechnology, 1:111-115.
Arditti J (1992) Fundamentals of orchid biology. New York, John Wiley \& Sons. 691p.

Cunha T, Cordeiro GM, Massaro R, Dezan LF \& Pedroso-deMoraes C (2011) Desenvolvimento in vitro de Laeliocattleya schilleriana Rolfe em meios de cultivo simplificados. Scientia Plena, 7:1-5.

Embrapa (1999) Manual de análises químicas de solos, plantas e fertilizantes. Brasília, Embrapa Comunicação para Transferência de Tecnologia. 370p.

Figueiredo MA, Pasqual M, Araújo AG, Junqueira KP, Santos FC \& Rodrigues VA (2008) Fontes de potássio no crescimento in vitro de plantas de orquídea Cattleya loddigesii. Ciência Rural, 38:255257.

George EF (1993) Plant propagation by tissue culture. Part 1: The Technology. $2^{\mathrm{a}}$ ed. Basingstoke, Exegetics Limited. 510p.

Hoagland DR \& Arnon DI (1950) The water culture method for growing plants without soil. California Agricultural Experiment Station. 32p.

Jones Jr. JB, Wolf B \& Mills HA (1991) Plant analysis handbook. Athens, Micro-Macro Publishing, Inc. 213p.

Knudson L (1946) A new nutrient solution for the germination of orchid seed. American Orchid Society Bulletin, 15:214-217.

Majerowicz N, Kerbauy GB, Nievola CC \& Suzuki RM (2000) Effects of nitrogen forms on dry matter partitioning and nitrogen metabolism in two contrasting genotypes of Catasetum fimbriatum (Orchidaceae). Environmental and Experimental Botany, 44:195-206.

Majerowicz N \& Kerbauy GB (2002) Effects of nitrogen forms on dry matter partitioning and nitrogen metabolism in two contrasting genotypes of Catasetum fimbriatum (Orchidaceae). Environmental and Experimental Botany, 47:249-258.

Marschner H (1995) Mineral nutrition of higher plants. London, Academic Press. 888p.

Murashige T \& Skoog F (1962) A revised medium for rapid growth and bio assays with tobacco tissue cultures. Physiology Plantarum, 15:473-493.

Novais RF \& Rodrigues DT (2004) Nutrição e fertilização de orquídeas. In: $4^{\circ}$ Congresso Brasileiro de Botânica, Viçosa. Anais. Sociedade Botânica do Brasil. CD-ROM.

Park SY, Murthy HN \& Paek KY (2002) Rapid propagation of Phalaenopsis from floral stalk-derived leaves. In vitro Cellular and Developmental Biology - Plant, 38:168-172.

Rego-Oliveira LV \& Faria RT (2005) In vitro propagation of Brazilian orchids using traditional culture media and commercial fertilizers formulations. Acta Scientiarum: Agronomy, 27:1-5.

Rodrigues DT, Novais RF, Alvarez V. VH, Dias JMM, Otoni WC \& Villani EM de A (2012) Cultivo in vitro de plântulas de orquídea em meios com diferentes concentrações de fertilizante mineral. Revista Ceres, 59:9-15

Shimura H \& Koda Y (2004) Micropropagation of Cypripedium macranthos var rebunense through protocorm-like bodies derived from mature seeds. Plant Cell Tissues Organic Culture, 78:273-276.

Stancato GC, Abreu MF \& Furlani AMC (2008) Crescimento de orquídeas epífitas in vitro: adição de polpa de frutos. Bragantia, 67:51-57.

Stancato GC \& Faria RT (1996) In vitro growth and mineral nutrition of the lithophytic orchid Laelia cinnabarina Batem (Orchidaceae) I: Effects of macro and microelements. Lindleyana, 11:41-43. 